\title{
MicroRNA-122-3p inhibits tumor cell proliferation and induces apoptosis by targeting Forkhead box $O$ in A549 cells
}

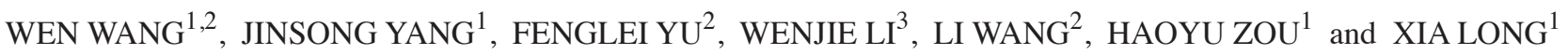 \\ ${ }^{1}$ Department of Cardio-Thoracic Surgery, Hunan Provincial People's Hospital, Changsha, Hunan 410005; \\ ${ }^{2}$ Department of Thoracic Surgery, The Second Xiangya Hospital of Central South University; ${ }^{3}$ Department of \\ Ophthalmology, The Third Xiangya Hospital of Central South University, Changsha, Hunan 410011, P.R. China
}

Received May 5, 2016; Accepted October 12, 2017

DOI: $10.3892 / \mathrm{ol} .2017 .7577$

\begin{abstract}
The imbalance between cell proliferation and apoptosis was implicated to serve key roles in cancer pathogenesis. The characteristics of microRNAs (miRNAs/miRs) have attracted much attention in research focusing on cancer pathogenesis in recent years. miR-122-3p has been reported to be associated with a number of disease processes and pathogenesis, including lung cancer. The present study aimed to investigate the association of miR-122-3p expression level with cell proliferation and apoptosis in a lung cancer cell line. A549 cells were transfected with miR-122-3p to interrupt the expression of miR-122-3p. Subsequently, MTT and BrdU assay, and western blot were used to analyze the influence of miR-122-3p on lung cancer cell proliferation, cell viability and its underlying mechanism. The present study revealed that, by targeting $\mathrm{p} 27$, overexpression of $\mathrm{miR}-122-3 \mathrm{p}$ inhibited cell proliferation in lung cancer. Furthermore, the cell apoptosis analysis suggested that overexpression of miR-122-3p was able to inhibit cell apoptosis by targeting Forkhead box O. These findings suggest that miR-122-3p may be associated with the pathology and progression of lung cancer and be a new therapeutic target for this disease.
\end{abstract}

\section{Introduction}

Lung cancer remains a leading cause of cancer-associated mortalities worldwide, despite considerable progress in the development of therapies. The prevalence and mortality rates

Correspondence to: $\mathrm{Dr}$ Jinsong Yang, Department of Cardio-Thoracic Surgery, Hunan Provincial People's Hospital, 61 Jiefang West Road, Changsha, Hunan 410005, P.R. China E-mail: yangjinsong0945@126.com

Dr Fenglei Yu, Department of Thoracic Surgery, The Second Xiangya Hospital of Central South University, 139 Middle Renmin Road, Changsha, Hunan 410011, P.R. China

E-mail: yufenglei894@sina.com

Key words: lung cancer, microRNA-122-3p, p27, Forkhead box O, A549 of lung cancer have increased worldwide (1-3). The detection and pathological research of lung cancer are important in the diagnosis and therapy of cancer diseases $(4,5)$. In view of this, it is necessary to elucidate the molecular mechanisms underlying cell proliferation and apoptosis in lung cancer cells.

The imbalance between cell proliferation and apoptosis has been implicated to serve key roles in cancer pathogenesis $(6,7)$. Accumulating evidence has indicated that microRNAs (miRNAs or miRs) serve a role in a number of cancer processes, including lung cancer (8-10). The results of previous studies have demonstrated that targeting or regulating miRNAs may identify novel ways to effectively overcome lung cancer resistance and personalize lung cancer therapy $(11,12)$. Therefore, as a type of small non-coding RNA, miRNA potentially serves roles in tumorigenesis and has attracted increasing attention.

Van Keuren-Jensen et al (8) recently revealed that miR-122-3p was significantly downregulated between early and advanced fibrosis of the liver. Another recent study by Wang et al (13) demonstrated that miR-122-3p exhibited significant association with either plasma cytokine and chemokine levels, or clinical features in patients with rheumatoid arthritis. Increasing evidences have indicated that miR-122-3p was downregulated in a number of types of cancer in humans, which suggested that miR-122-3p may serve a key role in tumorigenesis (14).

p27 and p21 are cell cycle regulators, which are reported to be associated with numerous types of tumor cell cycles, including liver, cervical and gastric cancer (15-17). Although these studies have demonstrated that p27 and p21 serve important roles in cell proliferation regulation, the mechanism underlying lung cancer remains to be elucidated.

Furthermore, Forkhead box $\mathrm{O}$ (FOXO) proteins belong to a family of proteins including FOXO1, FOXO3a, FOXO4 and FOXO6 in humans. Accumulating evidences have suggested that FOXO proteins function as tumor suppressors $(18,19)$.

The aim of the present study was to clarify the role of miR-122-3p in tumor growth of lung cancer cells. In the present study, A549 cells were transfected with control, miR-122-3p mimic or miR-122-3p inhibitor to affect miR-122-3p expression. Subsequently, an MTT assay was performed to detect cell proliferation. The results revealed that overexpression of miR-122-3p suppressed lung cancer cell proliferation. Subsequently, 5-bromo-2-deoxyuridine (BrdU) staining assay 
was performed to further investigate the mechanisms underlying miR-122-3p-induced cell growth inhibition. In addition, p27 was revealed to be upregulated by miR-122-3p. Finally, the present study analyzed FOXO, bim, and pro- and activated caspase-3 expression levels to clarify the mechanism underlying the effect of miR-122-3p on cell apoptosis regulation. The results demonstrated that miR-122-3p induced apoptosis by targeting FOXO in A549 cells. The present study provides theoretical basis and a new insight into the treatment of lung cancer.

\section{Materials and methods}

Cell culture. A549 cells were obtained from American Type Culture Collection (Manassas, VA, USA) and cultured in Dulbecco's modified Eagle's medium (DMEM; Invitrogen; Thermo Fisher Scientific, Inc., Waltham, MA, USA) supplemented with $10 \%$ fetal bovine serum (Invitrogen; Thermo Fisher Scientific, Inc.) at $37^{\circ} \mathrm{C}$ in $5 \% \mathrm{CO}_{2}$. The cells were transfected with mature miR-122-3p mimic (5'-AACAGC ACA AACUACUACCUCA-3') or miR-122-3p inhibitor (5'-UAUUUAGUGUGAUAAUGGCGUU-3'; both from Sigma-Aldrich; Merck KGaA, Darmstadt, Germany) using Lipofectamine ${ }^{\circledR} 2000$ (Invitrogen; Thermo Fisher Scientific, Inc.), according to the manufacturer's protocol. U6 (5'-AACGCTTCACGAATTTGCGT-3'; Sigma-Aldrich; Merck $\mathrm{KGaA}$ ) was selected as a miRNA control. In brief, miR-122-3p mimic or inhibitor and Lipofectamine ${ }^{\circledR} 2000$ reagent, diluted with $50 \mu \mathrm{l}$ antibiotic-free DMEM, were mixed and incubated for $20 \mathrm{~min}$ at room temperature. The cells $\left(5 \times 10^{3}\right.$ cells/well) were seeded onto a 96 -well plate and cultured with $400 \mu \mathrm{l}$ antibiotic-free DMEM. Then, the mixture was added to the cell culture plates and incubated at $37^{\circ} \mathrm{C}$ in $5 \% \mathrm{CO}_{2}$. Following $48 \mathrm{~h}$ transfection, the stably transfected cells were maintained for $\sim 4$ weeks by the culture medium containing $0.5 \mathrm{mg} / \mathrm{ml} \mathrm{G} 418$ (Sigma-Aldrich; Merck KGaA). G418-resistant cells were directly collected for use in subsequent experiments.

Cell proliferation and MTT assay. A549 cells were digested with $0.25 \%$ trypsin for $3 \mathrm{~min}$ at room temperature, re-suspended in $3 \mathrm{ml}$ culture medium and counted using a hemocytometer following exposure to Danshen extract (Xi'an Feida Bio-tech Co., Xi'an, China) every $2 \mathrm{~h}$ for $12 \mathrm{~h}$ (a total of 6 times). For the MTT assay, $5 \times 10^{3}$ cells/well were seeded onto 96 -well culture plates, exposed to $5 \mu \mathrm{g} / \mathrm{ml}$ Danshen and incubated for $2 \mathrm{~h}$ at $37^{\circ} \mathrm{C}$. Cell viability was then analyzed by adding $20 \mu \mathrm{l}$ $10 \mathrm{mg} / \mathrm{ml}$ MTT (Sigma-Aldrich) to $0.2 \mathrm{ml}$ culture medium and incubated for $3 \mathrm{~h}$ at $37^{\circ} \mathrm{C}$. Following removal of the medium, formazan (in dimethylsulfoxide) was added, and the $590 \mathrm{~nm}$ optical density was recorded using a Multiskan EX (Thermo Fisher Scientific, Inc.) (20).

BrdU assay. Cells were seeded in 6-well plates at a density of $2 \times 10^{4}$ cells/well on sterilized coverslips for $72 \mathrm{~h}$ at $37^{\circ} \mathrm{C}$. BrdU (Sigma-Aldrich; $10 \mu \mathrm{M}$ ) was added to the medium and incubated at $37^{\circ} \mathrm{C}$ for $5 \mathrm{~h}$. Cells were fixed in $70 \%$ ethanol for $5 \mathrm{~min}$ at $4^{\circ} \mathrm{C}$ followed by addition of $1.5 \mathrm{M} \mathrm{HCl}$ to the cells for $30 \mathrm{~min}$ at room temperature to denature DNA. Immunofluorescence to visualize incorporated BrdU was performed by using a mouse
anti-BrdU antibody (cat no. 555627; 1:1,000; BD Biosciences, San Jose, CA, USA) to incubate cells for $1 \mathrm{~h}$ at $37^{\circ} \mathrm{C}$. Then, incubation with secondary green-fluorescence dye-conjugated antibody (Alexafluor ${ }^{\circledR}$ 594; 1:1,000; Invitrogen; Thermo Fisher Scientific, Inc.) was subsequently performed for $45 \mathrm{~min}$ at $37^{\circ} \mathrm{C}$. VECTASHIELD mounting medium with DAPI (Vector Laboratories, Inc., Burlingame, CA, USA) was used to stain the nuclei for $5 \mathrm{~min}$ at room temperature. Images were visualized using a Leica inverted fully automated microscope (DMI6000B) at magnification, $\mathrm{x} 40$ with a digital camera DFC 420 RGB (Leica Microsystems GmbH, Wetzlar, Germany) (21). The Brdu labeling index (LI) was the number of Brdu-positive cells/the total number of cells in 10 fields and analyzed using SPSS version 19.0 (IBM Corp., Armonk, NY, USA).

Apoptosis assay. At $24 \mathrm{~h}$ following transfection, cells were harvested and suspended in Annexin-binding buffer (Thermo Fisher Scientific, Inc.) and then incubated with Annexin V-FITC Apoptosis Detection kit (Sigma-Aldrich; Merck KGaA) for $30 \mathrm{~min}$ in the dark at $25^{\circ} \mathrm{C}$. Apoptotic cells were subsequently analyzed using a FACS can (Beckman Coulter, Inc., Brea, CA, USA) and FlowJo version 10.4 (FlowJo LLC, Ashland, OR, USA) (6).

Western blot analysis. Cells were washed once with PBS and lysed in a radioimmunoprecipitation assay lysis buffer (Beyotime Institute of Biotechnology, Haimen, China) supplemented with Phenylmethanesulfonyl fluoride (Beyotime Institute of Biotechnology) for $30 \mathrm{~min}$ at $0^{\circ} \mathrm{C}$. Protein samples were measured the concentrations using Bradford Protein Assay kit (Beyotime Institute of Biotechnology) for $10 \mathrm{~min}$ at room temperature, boiled for $10 \mathrm{~min}$ in SDS sample buffer, then separated by SDS-PAGE and transferred to a nitrocellulose membrane. The membranes were incubated with primary antibodies (all dilution 1:1,000) overnight at $4^{\circ} \mathrm{C}$ following blocking with 5\% skim milk in TBS Tween-20 (TBST) for $1 \mathrm{~h}$ at room temperature. Membranes were washed once with TBST and incubated with horseradish peroxidase-conjugated secondary anti-rabbit antibody (cat. no., ab191866; $1 \mathrm{mg} / \mathrm{ml}$; Abcam, Cambridge, $\mathrm{UK}$ ) for $2 \mathrm{~h}$ at room temperature. WEST-ZOL-plus Western Blot Detection system (iNtRON Biotechnology, Sungnam, Korea) was used to visualize the protein bands. Antibodies specific to actin (cat no. 8457) were purchased from Cell Signaling Technology, Inc. (Danvers, MA, USA) and served as the internal control. Activated caspase-3 (cat no. ab2302), p27 (cat no. ab54563), p21 (cat no. ab7960) and pro-caspase-3 (cat no. ab32150) antibodies were obtained from Abcam. Bim (cat no. 2933), FOXO1 (cat no. 2880), FOXO3 (cat no. 2497) and phosphorylated FOXO1/3 (cat no. 9464) antibodies were purchased from Cell Signaling Technology, Inc. (22).

Statistical analysis. All experiments were repeated three times. Data are presented as the mean \pm standard deviation (SD). SPSS version 19.0 (IBM Corp.) was used for statistical analysis of data. Statistical significance was evaluated by one-way analysis of variance for multi-group comparisons with Bonferroni analyses or Student's t-test for two group comparisons. $\mathrm{P}<0.05$ was considered to indicate a statistically significant difference. 
A

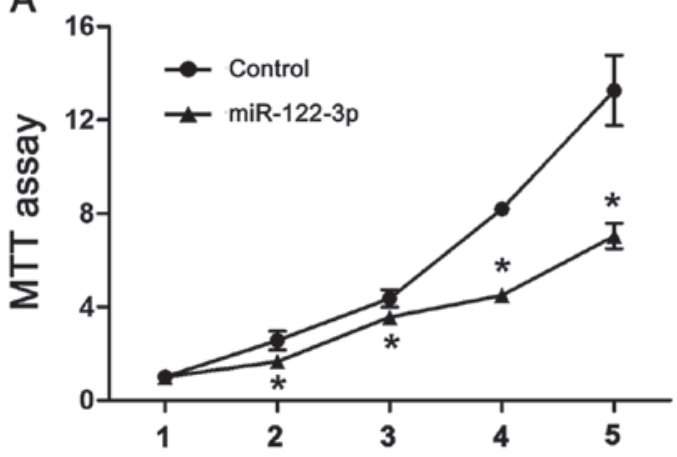

B

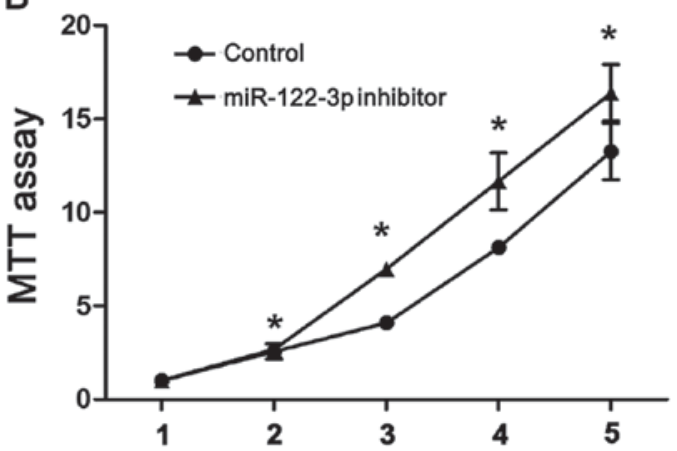

Figure 1. Effects of miR-122-3p expression on A549 cell proliferation. The cell viability of A549 cells transfected with (A) miR-122-3p mimic or (B) miR-122-3p inhibitor were analyzed by MTT assay. Inhibition of miR-122-3p downregulated cell proliferation of A549 cells. ${ }^{*} \mathrm{P}<0.05$ vs. the control group. miR, microRNA.

\section{Results}

Overexpression of miR-122-3p reduces cell proliferation in A549 cells. To analyze the effect of miR-122-3p on cell proliferation, A549 cells were transfected with the control (U6), miR-122-3p mimic or miR-122-3p inhibitor, and an MTT assay was performed. As demonstrated in Fig. 1, miR-122-3p overexpression significantly inhibited the proliferation of A549 cells compared with controls. Correspondingly, cells transfected with miR-122-3p inhibitor significantly increased A549 cell proliferation compared with controls $(\mathrm{P}<0.05)$.

miR-122-3p overexpression induces cell growth arrest via upregulation of p27 in A549 cells. To analyze the effect of miR-122-3p on cell proliferation, A549 cells were transfected with the control, miR-122-3p mimic or inhibitor, and BrdU staining was performed. To further investigate the mechanisms underlying miR-122-3p-induced cell growth inhibition, the present study analyzed the effect of miR-122-3p on various cell cycle regulators in A549 cells. BrdU positive cells were significantly decreased in the miR-122-3p mimic group and increased following miR-122-3p suppression compared with the control group $(\mathrm{P}<0.05$ and $\mathrm{P}<0.01$, respectively; Fig. $2 \mathrm{~A})$. Marked accumulation of $\mathrm{p} 27$ was detected in response to miR-122-3p expression. Conversely, $\mathrm{p} 21$ expression was not markedly affected by miR-122-3p expression (Fig. 2B).

Overexpression of miR-122-3p induces apoptosis in A549 cells. To analyze the effect of miR-122-3p on cell death, A549 cells were transfected with the control, miR-122-3p mimic or inhibitor, and an apoptosis assay was performed. As presented in Fig. 3, overexpression of miR-122-3p significantly increased the rate of apoptosis compared with the control group $(\mathrm{P}<0.01)$, while miR-122-3p suppression decreased apoptosis in A549 cells $(\mathrm{P}<0.05)$.

miR-122-3p induces apoptosis by targeting FOXO in A549 cells. To further investigate the mechanisms underlying the effect of miR-122-3p on apoptosis, A549 cells were transfected with the control, miR-122-3p mimic or inhibitor, and the expression levels of FOXO, bim, and pro- and activated caspase-3 were evaluated (Fig. 4). The results confirmed that A549 cell apoptosis was associated with the expression of FOXO. The western blot results of FOXO, bim, pro and

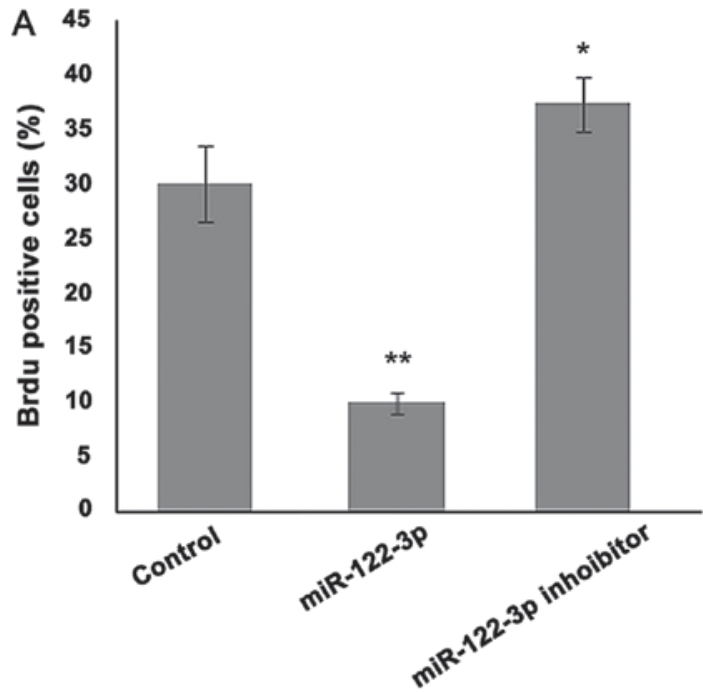

B

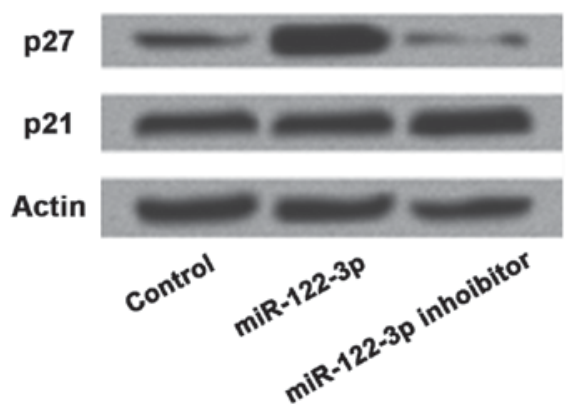

Figure 2. The effects of miR-122-3p expression on cell cycle regulator p27 were performed by BrdU staining and western blot. (A) A549 cells transfected with miR-122-3p mimic demonstrated a lower percentage of BrdU positive cells vs. the control group. (B) Western blot results showed a high expression level of p27 vs. the control group, whereas p21 was not affected by miR-122-3p expression. miR-122-3p upregulated p27 in the cell proliferation inhibition progress. ${ }^{*} \mathrm{P}<0.05 ;{ }^{* *} \mathrm{P}<0.01$ vs. the control group. $\mathrm{miR}$, microRNA; BrdU, 5-bromo-2-deoxyuridine.

activated caspase-3 expressions demonstrated that miR-122-3p promoted cell apoptosis by targeting FOXO.

\section{Discussion}

As one of the most common types of malignant tumors worldwide, lung cancer research has attracted increasing attention in research; however, there is currently no effective 

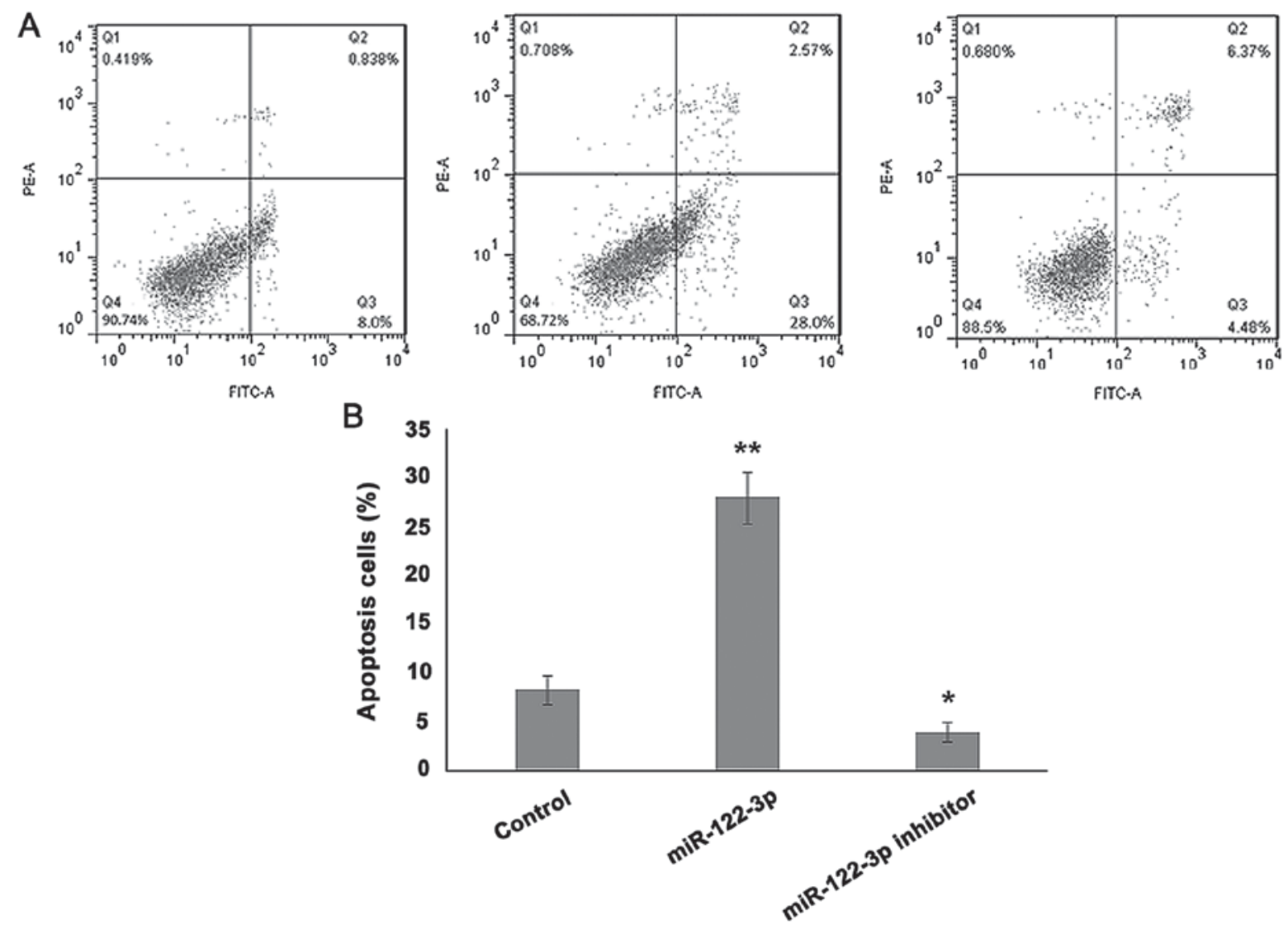

Figure 3. Effects of miR-122-3p expression on the apoptosis of A549 cells. The cell apoptosis percentage of A549 cells transfected with miR-122-3p mimic or miR-122-3p inhibitor was (A) analyzed by MTT assay and (B) quantified. Inhibition of miR-122-3p downregulated apoptosis of A549 cells. ${ }^{*} \mathrm{P}<0.05 ;{ }^{* * *} \mathrm{P}<0.01$ vs. the control group. miR, microRNA; PE-A, phycoerythrin-area; FITC-A, fluorescein isothiocyanate-area.

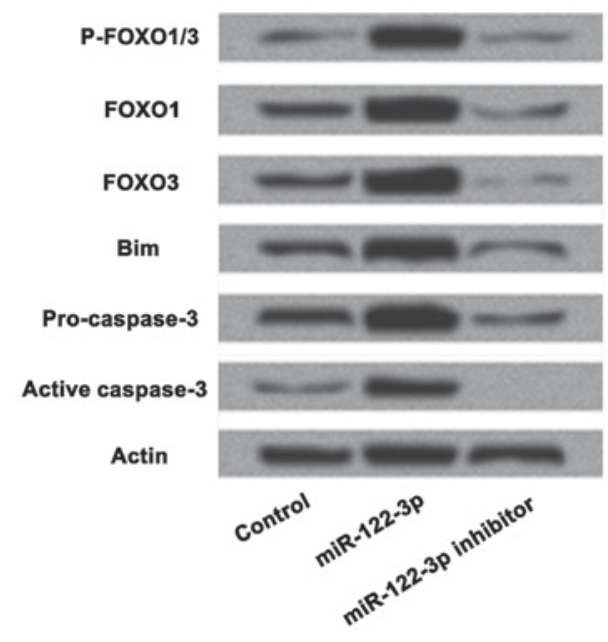

Figure 4. Association of miR-122-3p expression and FOXO on cell apoptosis. The expression levels of FOXO, bim, and pro- and activated caspase-3 was performed by western blot analysis. Inhibition of miR-122-3p downregulated the expression of FOXO. miR-122-3p induced apoptosis by targeting FOXO in A549 cells. miR, microRNA; FOXO, Forkhead box O; p, phosphorylated.

treatment strategy $(23,24)$. miRNA is a type of non-coding RNA molecule that inhibits the expression of target genes at multiple stages (25). As one of the most important regulators in the pathogenesis of human diseases, there are between 800 and 1,000 known miRNAs in the human genome that serve important roles in cancer cell progress regulation via the regulation of gene expression $(25,26)$. Certain miRNAs have been reported to serve key roles in the progression of human lung cancer, including miR-145 and miR-21 $(27,28)$.

The present study investigated the association between miR-122-3p and lung cancer, and revealed that miR-122-3p was associated with lung cancer cell proliferation. Furthermore, cell apoptosis was also an important mechanism associated with the progression of cancer. Therefore, a cell apoptosis assay was performed, which confirmed that miR-122-3p induced lung cancer apoptosis.

p27 and p21 are cell cycle regulators that are associated with numerous types of disease, demonstrating prognostic importance (29). Skirnisdottir and Seidal (30) previously evaluated the prognostic value of p21 alone and in combination with $\mathrm{p} 27$, and revealed that patients with non-serous tumors and concomitant p21 and p27 positivity patients exhibited excellent survival rates. In another study, p21 and p27 were reported to be associated with the cellular proliferation of lung cancer (31).

To fully elucidate the underlying mechanism of miR-122-3p on cancer cell proliferation of lung cancer, the present study performed BrdU staining and western blot analysis to evaluate the expression levels of p21 and p27. The results demonstrated that $\mathrm{p} 27$ was markedly accumulated in response to miR-122-3p expression, whereas p21 was not affected by miR-122-3p expression. Therefore, the present study concluded that miR-122-3p inhibits cell proliferation of lung cancer by upregulating p27 expression. 
FOXO proteins, as tumor suppressors, have been confirmed to regulate a number of cellular functions, including cell cycle, apoptosis, DNA damage repair and energy metabolism (32). In addition, FOXO overexpression and nuclear accumulation have been reported to be associated with reduced tumor growth, controlling cell homeostasis and cell fate (33).

In the present study, A549 cells were transfected with the control, miR-122-3p mimic or inhibitor, and the expression levels of FOXO, bim, and pro- and activated caspase-3 were determined. Apoptosis assay and western blot analysis were also performed. The results confirmed that miR-122-3p promotes cell apoptosis by targeting FOXO.

In summary, miR-122-3p inhibits cell proliferation by upregulating p27 expression and induces cell apoptosis by targeting FOXO in A549 lung cancer cells. These findings suggest that miR-122-3p may be associated with the progression of lung cancer and be a new therapeutic target for this disease.

\section{References}

1. Ferlay J, Steliarova-Foucher E, Lortet-Tieulent J, Rosso S, Coebergh JW, Comber H, Forman D and Bray F: Cancer incidence and mortality patterns in Europe: Estimates for 40 countries in 2012. Eur J Cancer 49: 1374-1403, 2013.

2. Utzschneider S, Wicherek E, Weber P, Schmidt G, Jansson V and Dürr HR: Surgical treatment of bone metastases in patients with lung cancer. Int Orthop 35: 731-736, 2011.

3. Ávila-Moreno F, Armas-López L, Álvarez-Moran AM, López-Bujanda Z, Ortiz-Quintero B, Hidalgo-Miranda A, Urrea-Ramírez F, Rivera-Rosales RM, Vázquez-Manríquez E, Peña-Mirabal E, et al: Overexpression of MEOX2 and TWIST1 is associated with $\mathrm{H} 3 \mathrm{~K} 27 \mathrm{me} 3$ levels and determines lung cancer chemoresistance and prognosis. PLoS One 9: e114104, 2014.

4. Tan C, Chen H and Wu T: Classification models for detection of lung cancer based on nine element distribution of urine samples. Biol Trace Elem Res 142: 18-28, 2011.

5. Ironmonger L, Ohuma E, Ormiston-Smith N, Gildea C, Thomson CS and Peake MD: An evaluation of the impact of large-scale interventions to raise public awareness of a lung cancer symptom. Br J Cancer 112: 207-216, 2015.

6. Zhang N, Su Y and Xu L: Targeting PKCe by miR-143 regulates cell apoptosis in lung cancer. FEBS Lett 587: 3661-3667, 2013.

7. Han SW and Roman J: Targeting apoptotic signaling pathways in human lung cancer. Curr Cancer Drug Targets 10: 566-574, 2010.

8. Van Keuren-Jensen KR, Malenica I, Courtright AL, Ghaffari LT, Starr AP, Metpally RP, Beecroft TA, Carlson EW, Kiefer JA, Pockros PJ and Rakela J: microRNA changes in liver tissue associated with fibrosis progression in patients with hepatitis $\mathrm{C}$. Liver Int 36: 334-343, 2016.

9. Maftouh M, Avan A, Galvani E, Peters GJ and Giovannetti E: Molecular mechanisms underlying the role of microRNAs in resistance to epidermal growth factor receptor-targeted agents and novel therapeutic strategies for treatment of non-small-cell lung cancer. Crit Rev Oncog 18: 317-326, 2013.

10. Rolfo C, Fanale D, Hong DS, Tsimberidou AM, Piha-Paul SA, Pauwels P, Van Meerbeeck JP, Caruso S, Bazan V, Cicero G, et al: Impact of microRNAs in resistance to chemotherapy and novel targeted agents in non-small cell lung cancer. Curr Pharm Biotechnol 15: 475-485, 2014.

11. Gong Z, Yang J, Li J, Yang L, Le Y, Wang S and Lin HK: Novel insights into the role of microRNA in lung cancer resistance to treatment and targeted therapy. Curr Cancer Drug Targets 14: 241-258, 2014.

12. MacDonagh L, Gray SG, Finn SP, Cuffe S, O'Byrne KJ and Barr MP: The emerging role of microRNAs in resistance to lung cancer treatments. Cancer Treat Rev 41: 160-169, 2015.

13. Wang W, Zhang Y, Zhu B, Duan T, Xu Q, Wang R, Lu L and Jiao Z: Plasma microRNA expression profiles in Chinese patients with rheumatoid arthritis. Oncotarget 6: 42557-42568, 2015.
14. Shi Y and Huang A: Effects of sorafenib on lung metastasis in rats with hepatocellular carcinoma: The role of microRNAs. Tumour Biol 36: 8455-8463, 2015.

15. Kim JH, Choi YK, Byun JK, Kim MK, Kang YN, Kim SH, Lee S, Jang BK and Park KG: Estrogen-related receptor $\gamma$ is upregulated in liver cancer and its inhibition suppresses liver cancer cell proliferation via induction of p21 and p27. Exp Mol Med 48: e213, 2016.

16. Thacker PC and Karunagaran D: Curcumin and emodin down-regulate TGF- $\beta$ signaling pathway in human cervical cancer cells. PLoS One 10: e0120045, 2015.

17. Zhang E, Yin D, Han L, He X, Si X, Chen W, Xia R, Xu T, Gu D, De W, et al: E2F1-induced upregulation of long noncoding RNA LINC00668 predicts a poor prognosis of gastric cancer and promotes cell proliferation through epigenetically silencing of CKIs. Oncotarget 7: 23212-23226, 2016.

18. Huang $\mathrm{H}$ and Tindall DJ: Regulation of FOXO protein stability via ubiquitination and proteasome degradation. Biochim Biophys Acta 1813: 1961-1964, 2011

19. Wang F, Chan CH, Chen K, Guan X, Lin HK and Tong Q: Deacetylation of FOXO3 by SIRT1 or SIRT2 leads to Skp2-mediated FOXO3 ubiquitination and degradation. Oncogene 31: 1546-1557, 2012.

20. Lu L, Li C, Li D, Wang Y, Zhou C, Shao W, Peng J, You Y, Zhang $X$ and Shen X: Cryptotanshinone inhibits human glioma cell proliferation by suppressing STAT3 signaling. Mol Cell Biochem 381: 273-282, 2013.

21. Fernandez S, Risolino M, Mandia N, Talotta F, Soini Y, Incoronato M, Condorelli G, Banfi S and Verde P: miR-340 inhibits tumor cell proliferation and induces apoptosis by targeting multiple negative regulators of p27 in non-small cell lung cancer. Oncogene 34: 3240-3250, 2015.

22. Nam KS, Oh S, Lee KM, Yoo SA and Shin I: CD44 regulates cell proliferation, migration, and invasion via modulation of c-Src transcription in human breast cancer cells. Cell Signal 27: 1882-1894, 2015.

23. Zhang Y, Zhao J, Qiu L, Zhang P, Li J, Yang D, Wei X, Han Y, Nie S and Sun Y: Co-expression of ILT4/HLA-G in human non-small cell lung cancer correlates with poor prognosis and ILT4-HLA-G interaction activates ERK signaling. Tumor Biol 37: 11187-11198, 2016.

24. Lysov Z, Dwivedi DJ, Gould TJ and Liaw PC: Procoagulant effects of lung cancer chemotherapy: Impact on microparticles and cell-free DNA. Blood Coagul Fibrinolysis 28: 72-82, 2017.

25. Yongchun Z, Linwei T, Xicai W, Lianhua Y, Guangqiang Z, Ming Y, Guanjian L, Yujie L and Yunchao H: MicroRNA-195 inhibits non-small cell lung cancer cell proliferation, migration and invasion by targeting MYB. Cancer Lett 347: 65-74, 2014.

26. Koturbash I, Zemp FJ, Pogribny I and Kovalchuk O: Small molecules with big effects: The role of the microRNAome in cancer and carcinogenesis. Mutat Res 722: 94-105, 2011.

27. Hu J, Qiu M, Jiang F, Zhang S, Yang X, Wang J, Xu L and Yin R: MiR-145 regulates cancer stem-like properties and epithelial-to-mesenchymal transition in lung adenocarcinoma-initiating cells. Tumour Biol 35: 8953-8961, 2014.

28. Xu L, Huang Y, Chen D, He J, Zhu W, Zhang Y and Liu X: Downregulation of miR-21 increases cisplatin sensitivity of non-small-cell lung cancer. Cancer Genet 207: 214-220, 2014

29. Zhang M, Li J, Wang L, Tian Z, Zhang P, Xu Q, Zhang C, Wei F and Chen W: Prognostic significance of p21, p27 and survivin protein expression in patients with oral squamous cell carcinoma. Oncol Lett 6: 381-386, 2013.

30. Skirnisdottir I and Seidal T: Association of p21, p21 p27 and p21 p53 status to histological subtypes and prognosis in low-stage epithelial ovarian cancer. Cancer Genomics Proteomics 10: 27-34, 2013.

31. Li ZC, Zhang LM, Wang HB, Ma JX and Sun JZ: Curcumin inhibits lung cancer progression and metastasis through induction of FOXO1. Tumour Biol 35: 111-116, 2014.

32. Shukla S, Rizvi F, Raisuddin S and Kakkar P: FoxO proteins' nuclear retention and $\mathrm{BH} 3$-only protein Bim induction evoke mitochondrial dysfunction-mediated apoptosis in berberine-treated HepG2 cells. Free Radic Biol Med 76: 185-199, 2014.

33. Bucur O, Stancu AL, Muraru MS, Melet A, Petrescu SM and Khosravifar R: PLK1 is a binding partner and a negative regulator of FOXO3 tumor suppressor. Discoveries (Craiova) 2: pii: e16, 2014. 